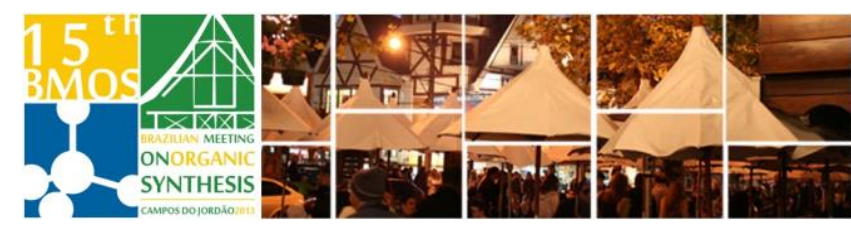

\title{
Benzothiadiazole-triazole-linked biologically active lapachone derivatives: Antitumoral activity and bioimaging application
}

\author{
Eduardo H. G. da Cruz, ${ }^{a}$ Pedro H. P. R. Carvalho, ${ }^{b}$ Diego A. C. da Silva, ${ }^{a}$ Emilay B. T. \\ Diogo, ${ }^{a}$ Claudia Pessoa, ${ }^{c}$ Bruno Coêlho, ${ }^{c}$ Brenno A. D. Neto ${ }^{b^{*}}$ e Eufrânio N. da Silva \\ Júnior ${ }^{\mathrm{a}^{*}}$
}

aInstituto de Ciências Exatas, Departamento de Química, UFMG, MG, Brazil; bInstituto de Química, UnB, DF,

Brazil. 'Departamento de Fisiologia e Farmacologia, UFC, CE, Brazil.

*brenno.ipi@gmail.com, eufranio@ufmg.br

Keywords: Quinone, Benzothiadiazole and Photoluminescence.

\section{INTRODUCTION}

Lapachone derivatives are well known for their notable efficiency against many cancer cell lines. ${ }^{1}$ These compounds are virtually nonfluorescent, therefore a visual tracking to help in the elucidation of their mechanisms and targets inside the cell are a hard task.

In order to surpass this major drawback, a naphthoquinone derivative were joint together with a BTD (2,1,3-benzothiadiazole) core, already known for its photoluminescent properties, ${ }^{2}$ affording a fluorescent compound that could be tracked inside the cell (Scheme 1).

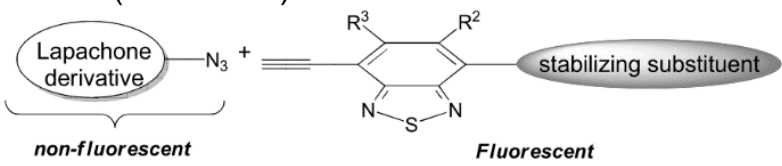

Scheme 1. BTD and naphthoquinone cores linked by a triazole moiety.

\section{RESULTS AND DISCUSSION}

The BTD-triazole-linked lapachone derivative were synthesized via the click reaction ${ }^{3}$ between $\mathbf{1}$ and 2, affording $\mathbf{3}$. Then $\mathbf{3}$ was treated with o-phenylenediamine to afford 4 (Scheme 2).

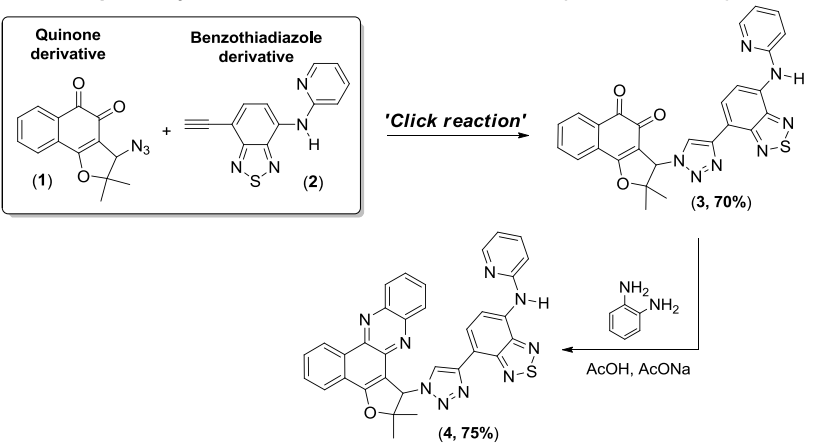

Scheme 2. Synthetic route aiming at antitumor compounds $\mathbf{3}$ and $\mathbf{4}$.

Compound $\mathbf{3}$ proved to be highly active against the tested cancer cell lines and very selective compared with the positive control (Doxorubicin), yet it provided poor results in bioimaging experiments due to its low fluorescent intensity. The BTD derivative 4, however, did not present activity against the tested cancer cells, most probably due to the absence of the redox center (quinonoid group). Nevertheless, it presented good fluorescence emission and very interesting results in bioimaging experiments (Figure 1).

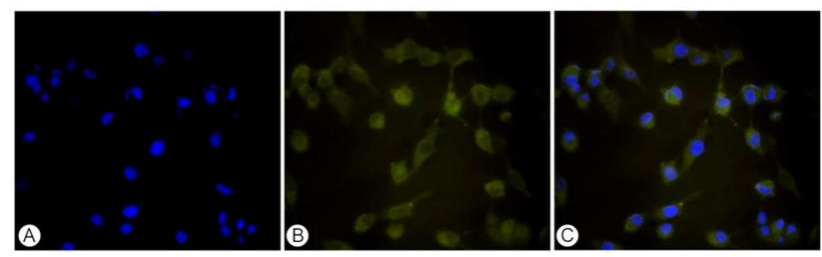

Figure 1. (A) Shows the nucleus staining with DAPI (blue). (B) Shows a fluorescence pattern associated with perinuclear region plus a slight homogenous stain through the cell cytoplasm (green) obtained with 4 . (C) Overlapping of DAPI and $\mathbf{4}$ staining patterns.

\section{CONCLUSION}

We have described the synthesis of a new antitumoral compound. Substance 3 was considered highly activity against the tested cancer cell lines. Substance $\mathbf{4}$ did not showed activity against any the cancer cells, yet it is a interesting compound for the purpose of indicating the preferential target and mechanisms of action of $\mathbf{3}$ inside the cell.

\section{ACKNOWLEDGEMENTS}

CNPq, CAPES, FAPDF, FAPEMIG, INCTcatálise, DPP-UnB.

\section{REFERENCES}

${ }^{1}$ Oliveira, L. G.; Silva, M. M.; Paula, F. C. S.; Pereira-Maia, E. C.; Donnici, C. L.; Simone, C. A.; Frézard, F.; Silva Júnior, E. N.; Demicheli, C. Molecules. 2011, 16, 10314.

${ }^{2}$ Neto, B. A. D.; Lapis, A. A. M.; da Silva Júnior, E. N.; Dupont, J. Eur. J. Org. Chem. 2013, 228.

${ }^{3}$ Rostovtsev, V. V.; Green, G. L.; Fokin, V. V.; Sharpless, K. B.; Angew. Chem. Int. Ed. 2002, 41, 2596-2599. 